\title{
How to be an uncompromising revisionary ontologist
}

\author{
[draft; please cite the final version, which is forthcoming in Synthese]
}

\begin{abstract}
Revisionary ontologies seem to go against our common sense convictions about which material objects exist. These views face the so-called Problem of Reasonableness: they have to explain why reasonable people don't seem to accept the true ontology. Most approaches to this problem treat the mismatch between the ontological truth and ordinary belief as superficial or not even real. By contrast, I propose what I call the "uncompromising solution". First, I argue that our beliefs about material objects were influenced by evolutionary forces that were independent of the ontological truth. Second, I draw an analogy between the Problem of Reasonableness and the New Evil Demon Problem and argue that the revisionary ontologist can always find a positive epistemic status to characterize ordinary people's beliefs about material objects. Finally, I address the worry that the evolutionary component of my story also threatens to undermine the best arguments for revisionary ontologies.
\end{abstract}

"I simply want to strongly emphasize that nihilists never just say,

'there are no toasters; revise your breakfast plans'” (Bennett 2009)

\section{Revisionary ontologies and the Problem of Reasonableness}

Revisionary ontologies seem to disagree with common sense about which material objects exist - about the "ontological truth", as I will put it. For example, common sense posits dogs and rocks, but not scattered “dog-rocks". So any ontology that doesn't include dogs and rocks, or also includes dog-rocks, is revisionary. ${ }^{1}$ Most metaphysicians subscribe to some revisionary ontology or other. Abundant ontologies posit vastly more objects than common sense countenances: for instance, according to Universalism any objects whatsoever compose something. ${ }^{2}$ Sparse ontologies, on the other hand, posit fewer objects: according to Nihilism

\footnotetext{
${ }^{1}$ Note the qualification 'seem to' in my characterization. "Compatibilists" such as van Inwagen (2014: 10) insist that the tension between their views and common sense is merely apparent and consequently reject the label 'revisionary'. These metaphysicians still count as revisionary in my sense. See below for more on compatibilist and incompatibilist strategies.

2 See Lewis 1986, Sider 2001, and further works to be cited in the footnotes of section 3.
} 
there are no composite objects, while according to Organicism the only ones are biological organisms. ${ }^{3}$ Revisionary ontologists have arguments for these views (some of which we will review in due course), but even after having provided them, they need to explain why otherwise reasonable people appear to hold massively false beliefs about which material objects exist ("ontological beliefs"). Call this the Problem of Reasonableness. ${ }^{4}$ In what follows I will refer to those whose beliefs are to be explained as "ordinary people", by which I simply mean those untainted by revisionary theorizing.

Some might protest that rather than denying the existence of tree-dogs, ordinary people more likely just never gave thought to the matter. Surprisingly, this is largely irrelevant to the problem at hand. It is both independently plausible and strongly suggested by a recent empirical study of Rose and Schaffer (2017) that most people would deny the existence of tree-dogs if they were asked to reflect on the matter. More cautiously, while Rose and Schaffer's study is subject to interpretation, it's safe to say that it establishes at least that ordinary people are not natural universalists. ${ }^{5}$ If so, it behooves the universalist to explain

\footnotetext{
${ }^{3}$ See Rosen and Dorr 2002 for Nihilism and van Inwagen 1990 for Organicism. To simplify things, in what follows I will pretend that "liberal eliminativists", who believe in a large number of objects that nonetheless lack the right modal profile to qualify as ordinary (Unger 1979, Heller 1990), believe in ordinary objects.

${ }^{4}$ See Hirsch 2002: 116; the label comes from Korman 2009.

${ }^{5}$ For example, in their studies the folk appear to intuit that two people shaking hands, two mice glued together, or some rocks randomly scattered over one's yard, don't compose anything (unless they serve a purpose). Rose and Schaffer conclude that the folk's beliefs about composition are heavily influenced by teleological thinking, but we don't need to take a stance about whether they are right about that (see Korman and Carmichael 2017 for some criticisms). It's enough to observe that when prompted to say whether composition occurs, the folk will often say 'No'.
} 
why ordinary people are prone to forming false beliefs about composition, even if they didn't have them before.

Why care? First, the Problem of Reasonableness threatens to show that many ordinary belief-forming procedures are unreliable; whatever problem the revisionist points out with our ontological beliefs, she will have to explain why it doesn't also affect the premises she relies on when arguing against these beliefs. ${ }^{6}$ Second, solving the problem might help rebut a deflationary line of argument for common sense ontology, developed by Eli Hirsch. ${ }^{7}$ Hirsch argues that charity considerations require us to interpret ordinary people's utterances without attributing egregious perceptual and a priori errors to them, and that we should therefore interpret them as speaking the truth in their own idiolect. Armed with a solution to the Problem of Reasonableness, revisionists could respond that such errors are quite understandable and don't prevent ordinary people's beliefs from being reasonable. ${ }^{8}$

Most solutions to the problem deny a radical mismatch between common sense and the ontological truth. Compatibilists claim that the tension is merely apparent: ordinary people's beliefs aren't incompatible with the target ontology. ${ }^{9}$ Incompatibilists, by contrast, concede that

\footnotetext{
${ }^{6}$ See sections 4-5, van Inwagen 1990: 103, and Korman 2009, 2014, 2016: Ch. 7.

${ }^{7}$ See Hirsch 2002, 2005.

${ }^{8}$ Cf. McGrath 2008

9 The expression 'compatibilism' was first introduced into the debate by O’Leary-Hawthorne and Michael 1996. See Chisholm 1976: Ch. 3, Heller 1990: 14 and Thomasson 2007: 183-185 for loose talk, Lewis 1986: 213 for implicit quantifier domain restriction, van Inwagen 1990: Chs. 10-11 for context-sensitivity, Liggins 2008 for syntactically singular but semantically plural expressions, Horgan and Potrč 2008: Chs. 4-5 for contextrelativized propositions, and Sattig 2015 for systematic ambiguity between material and formal predication. Cameron (2008) and Schaffer (2009: 356-362) attempt to recast debates seemingly about what exists as debates
} 
the conflict is genuine but add that ordinary people's beliefs are either close enough to the truth or not deeply held. ${ }^{10}$

Unfortunately, these conciliatory strategies suffer from serious difficulties; here I will just briefly mention the most important ones. Many extant solutions are committed to implausible semantic or psychological hypotheses. ${ }^{11}$ Others do little to explain why ordinary people make the errors they make ${ }^{12}$ or reframe the disputes in ways that prevent the standard arguments from supporting the positions they were originally designed to support. ${ }^{13}$ Yet others give rise to versions of the very problems revisionists wanted to solve by going revisionary. ${ }^{14}$ Finally, some views are committed to systematic paraphrases with severe expressive limitations. ${ }^{15}$

It's fair to say that each conciliatory solution suffers from at least some of these problems. Perhaps revisionary ontologists should learn to accept that common sense is wide off the mark with respect to when composition occurs. In section 2, I will offer a twopronged uncompromising solution to the Problem of Reasonableness. First, I will argue that it's unsurprising if ordinary people's ontological beliefs are false, since the selective pressures about what is fundamental; Sider (2004: 680-681, 2013), Dorr (2005: 248-250), and Cameron (2010) suggest that we understand them as concerning what exists in the most joint-carving sense of 'exists'.

${ }^{10}$ Merricks 2001: Ch. 7 is an example of the former strategy, while Rosen and Dorr 2002 and Eklund 2005 are examples of the latter.

11 O’Leary-Hawthorne and Michael 1996, Merricks 2001: 163-170, Hirsch 2002: 109-111, Korman $2008,2009$. See Keller 2015, though, for a contrasting view.

12 Korman 2009

${ }^{13}$ Korman 2009: 248; 2015; 2016: Ch. 6

${ }^{14}$ Eklund 2002: 250, McGrath 2005, Bennett 2009: 66-71

15 Uzquiano 2004 
that shaped them were independent of the ontological truth. Next, I will draw a parallel between the Problem of Reasonableness and the New Evil Demon Problem to argue that these beliefs are nonetheless reasonable. In section 3, I will address the worry, recently raised by Daniel Korman, that this evolutionary story undermines the very premises revisionary ontologists rely on when arguing for their own views. Due to space limitations, I cannot offer an exhaustive discussion; it will have to do to show that the core arguments for two familiar positions, Organicism (section 4) and Universalism (section 5), survive debunking. I will conclude that the uncompromising view provides an attractive and hitherto overlooked solution to the Problem of Reasonableness.

\section{A two-pronged solution to the Problem of Reasonableness}

A satisfactory solution to the Problem of Reasonableness should explain (a) why it's not surprising that ordinary people's ontological beliefs came apart from the ontological truth (the causal component), and (b) why these beliefs are reasonable (the evaluative component). Below I offer a two-pronged solution that addresses both questions. Although other sources (e.g. memory and testimony) also influence our beliefs about which objects there are, I will restrict my attention to perceptual ontological beliefs. Plausibly, the challenge posed by the Problem of Reasonableness is significantly diminished once we have a satisfactory story about these.

\subsection{The causal component}

In what follows, I will outline the sketch of a broadly evolutionary account of why ordinary people's ontological beliefs diverge from the ontological truth. Before I present the account itself, I should flag two potential limitations to its scope. The first is the one mentioned 
above: I only intend to explain why people don't accept any particular revisionary ontology, not why they accept the particular ontology of ordinary objects that they actually do. I will return to the difference between the two explananda at the end of this section, but in a nutshell, to account for the particular ontology that ordinary people accept is a much more ambitious and empirically involved project. By contrast, we may discharge the burden of explaining why we aren't inclined to accept any of the revisionary ontologies on the market by giving a relatively sketchy story (even then, the story shouldn't be entirely speculative; I relegated references to the empirical literature to the footnotes ${ }^{16}$.)

The second limitation is that evolution by itself is unlikely to yield a full explanation; our beliefs were much more likely influenced by a combination of evolutionary and cultural factors. ${ }^{17}$ In the present context I still think that it's justified to primarily focus on the role of evolution in shaping our ontological beliefs, for two reasons. First, there is reason to think that culture played a less pronounced role in influencing our ontological beliefs than evolution did. One data point in favor of this hypothesis is that ordinary people appear to have remarkably similar ontological beliefs across different cultures. In comparison to the pervasive and fairly obvious cross-cultural differences that characterize moral, religious and aesthetic beliefs, it is much harder to find clear cases in which the members of one culture typically think that certain objects compose another object while the members of another culture typically think that they don't. Second, culture is most likely to have influenced our beliefs about artifacts and other intentionally created objects (e.g. social objects like states, assuming they are material objects in the first place). But the proper subset of ordinary

\footnotetext{
${ }^{16}$ See Osborne 2016 for more thorough discussions of the relevant empirical literature.

17 Thanks to an anonymous referee for raising this concern.
} 
people's ontological beliefs that doesn't concern such things (roughly: beliefs only about objects found in nature) is already incompatible with all of the major revisionary ontologies. So, even if the evolutionary story doesn't fully explain why our ontological beliefs are what they are, it might still give a satisfactory account of the divergence between our ontological beliefs and the ontological truth.

Here, then, is the account. Evolution shaped our ontological beliefs by shaping our tendencies to form them: some dispositions were useful when interacting with the environment, and beings with these dispositions were likelier to entertain beliefs with certain contents. Tendencies to form beliefs about a subject matter are at the right level of generality for an evolutionary account of a range of beliefs. The hypothesis is not that evolution affected our general reasoning capacity so as to make it likelier that we would form beliefs of a certain kind (that would be insufficiently specific for a satisfactory account of the divergence between our ontological beliefs and the ontological truth). Nor is it that evolution directly affected the contents of individual beliefs (this would be empirically implausible, since token beliefs are not heritable traits). Rather, the target of the explanation I'm offering is something in between, i.e. something more specific than our general reasoning capacities but more general than token beliefs. Street (2006: 117-120) has in mind a similar notion when she speaks of evaluative tendencies. In a similar fashion, our early ancestors had ontological tendencies: dispositions to assign certain qualities to a single object. For example, when they encountered greenish, trunky, leafy qualities, they tended to represent them as belonging to the same thing (a tree). Call tendencies to represent the environment as containing certain objects positive ontological tendencies.

Clearly, uncompromising sparse revisionists will rely heavily on our positive ontological tendencies when providing the causal component. One might then expect that 
uncompromising abundant revisionists would likewise make use of negative ontological tendencies: tendencies to treat certain regions as if they didn't contain objects of a certain kind. But are there such things as negative ontological tendencies? This is a somewhat tricky question. There is a clear difference between not believing that there are dog-rocks and believing that there are no dog-rocks. It's less obvious what the difference is between not having the tendency to treat a region as if it contained an object and having the tendency to not treat a region as if it contained one. In any case, if you think there is a difference, let's focus on the (perhaps weaker) claim that that our ancestors lacked the ontological tendency to form beliefs about dog-rocks, trout-turkeys, and other unusual objects. Abundant ontologists need not assume anything stronger than that. For plausibly, under the right circumstances, the absence of a disposition to treat certain regions as containing an object is sufficient for forming the belief that the object in question doesn't exist. For example, if S lacks the tendency to treat regions containing matter arranged dog-wise and matter arranged rock-wise as containing dog-rocks and is asked to reflect on whether she believes that there are dog-rocks, S will plausibly form the belief (if she didn't already have it) that there are no dog-rocks. In a broad sense, beliefs like this are perceptual too. Perhaps S has perceptual experience as of various composite objects and forms the belief that there are no dog-rocks because she doesn't find them represented in her perceptual experience. Alternatively, she might only have perceptual experiences as of raw qualities distributed over matter, and (when asked to reflect) forms the belief that there are no dog-rocks because she doesn't find herself disposed to spontaneously form the belief that there are. Either way, the sheer absence of abundant ontological tendencies seems sufficient for ordinary people to form the belief, at least sometimes and at least on reflection, that there are no arbitrary scattered objects. This is all the uncompromising abundant revisionist needs. 
How can this sketchy story give us the causal component? Keep in mind that we aren't looking for an explanation of ordinary people's ontological beliefs. All we need to explain is why they weren't likely to end up with the true ontology of material objects. One way to explain this is by arguing that for any particular revisionary ontology (not just the true one), we were unlikely to have ended up believing that ontology. And to make this claim plausible, we need not suppose anything stronger than that ordinary ontological tendencies weren't maladaptive, which is a reasonable assumption. Evolution selects for the ability to track and interact with qualified portions of matter, and the tendency to accept common sense ontology is compatible with having this ability. For example, for the purpose of avoiding the dangers posed by tigers, what matters is the capacity to track tigerish qualities distributed over matter. This role can be fulfilled by dispositions to posit pieces of matter arranged tigerwise, conjoined pairs of tiger halves that always move together, or even by the disposition to track tiger-rock fusions but focus on their tigerish aspects whenever we notice them. But it's also fulfilled by just positing tigers; so, the tendency to believe in tigers wasn't maladaptive.

It is important to emphasize that the story above claims merely that our ordinary ontological tendencies weren't maladaptive. There are a number of ways this could be true. Perhaps there are numerous equally adaptive ways of carving up the world into objects, and common sense ontology is only one of them. On this hypothesis it was mere chance that we ended up with the carving that corresponds to common sense ontology, and there is no deeper story to be told about why are natural moderate ontologists rather than (say) natural nihilists or universalists.

A more ambitious explanation would contend that carving up the world into objects roughly in the way we tend to wasn't merely not maladaptive but also positively adaptive. Here's one way such an explanation could go. It plausibly made a difference to our 
ancestors' chances of survival which matter-filled regions they took to be occupied by a composite object. In particular, whenever a plurality of objects in $\mathrm{R}$ were arranged in a more or less spatiotemporally continuous manner, were easy to distinguish from their background, and acted in concert (in what follows: they were cohesive), it was useful to believe that there was a medium-sized object in $\mathrm{R}^{18}$ This is because the pluralities of objects that had the greatest impact on our ancestors' lives - the pluralities that occupied regions of space our ancestors thought were also occupied by food, predators, shelter, enemies, and the like were usually cohesive. However, it is generally unnecessary and cognitively costly (if at all possible) to precisely track the movement of a large plurality of objects. The members of even a very cohesive plurality don't keep together perfectly (if they did, we wouldn't think that ordinary objects can change their parts). So what's really needed is just the ability to approximately track the movement of cohesive pluralities. And this purpose is well served by positing a middle-sized object in regions occupied by those pluralities whose approximate tracking would promote survival. ${ }^{19}$ On the other hand it was not particularly useful to track the behavior of objects in non-cohesive pluralities, so it was not useful to form the

${ }^{18}$ Lewis (1986: 211) and van Cleve (1986: 144-146) mention the same folk criteria - apparent spatial continuity, easy distinguishability from the background, and joint movement - of composition. Similar criteria have been proposed in cognitive psychology (Spelke 1990) and cognitive science (Taraborelli 2002: 1). See especially Spelke's four principles of object recognition: the principles of cohesion, boundedness, rigidity, and no action at a distance (1990: 49). For a general survey of the "binding problem(s)", see Roskies 1999.

19 See Alvarez (2011) on the phenomenon of ensemble representation, one kind of which is the representation of several objects as one. Generally, ensemble representations compress data and thereby achieve cognitive economy at the cost of some loss of information. 
corresponding ontological beliefs either. This way, we ended up believing in more or less the objects of our folk ontology.

A third option is to develop an account that combines elements of the modest and the ambitious strategy. For example, one could argue that although folk ontological tendencies are fairly adaptive, there are numerous equally (and perhaps even more) adaptive ways of carving up the world into objects; it's just that most of these ways were ruled out by antecedent biological constraints on our ancestors' visual system. ${ }^{20}$ In that case, the explanation of our ontological beliefs would be biological but only partly evolutionary: it would be a mix of natural selection and biological constraints (some of them mere byproducts of natural selection) that led to our present ontological beliefs.

To drive the main point of the last few paragraphs home: the minimal core of the causal component is that there is no reason to expect that we would stumble upon any revisionary ontology, including the true one. Although I officially don't need to commit myself to anything stronger than this minimal core, an evolutionary account of the ontological beliefs we actually have may well be possible. However, fully establishing such an account would be a much more ambitious project than I can undertake here. Before concluding this section, I will consider two concerns that arise regarding the causal component.

The first one goes as follows. ${ }^{21}$ Our object concepts cannot be detached from the realworld environment in which they were formed. More pointedly: perhaps the conditions under which we are disposed to use the concept of a certain kind of object, $\mathrm{O}$, constitute sufficient application conditions for the concept $O$. This idea constitutes the heart of the

\footnotetext{
${ }^{20}$ Cf. Singh and Hoffman 2013: 181-182.

${ }^{21}$ Thanks to an anonymous referee for raising this objection.
} 
analytic deflationist view that Amie Thomasson defended in a number of works (see especially 2007 and 2015). The truth of analytic deflationism would not bode well for the uncompromising strategy. Suppose we are disposed to apply the concept tiger whenever we are faced with a portion of matter arranged tiger-wise. Then, the analytic deflatonist says, the rules of use guiding 'tiger' will be such that the existence of some portion of matter arranged tiger-wise in $\mathrm{R}$ will by itself entitle us to assert the sentence 'There is a tiger in R'. But then there are tigers, after all, which would mean that uncompromising nihilists couldn't even coherently state the causal component.

My response to this worry is twofold. First: it hardly needs saying that analytic deflationism is a highly controversial view. Some reject it on the basis of a general skeptical stance about analyticity (Sider 2011: 191-7). My own position, which I will merely state without elaborating (but see the next footnote for more detailed defenses), is that the main culprit is the move from entitlement or justification to truth (henceforth I will put things in terms of justification, but nothing hangs on this). The rules of use guiding a concept $\mathrm{F}$ in conjunction with F's application conditions may indeed justify (perhaps even a priori justify) the belief that there is an F. But such justification is defeasible, and the arguments familiar from the literature on material-object metaphysics are exactly the kinds of things that could serve as suitable defeaters. So even if the rules of use guiding tiger justify us in forming the belief that there is a tiger in $\mathrm{R}$ whenever there is some matter arranged tiger-wise in $\mathrm{R}$, our justification is defeasible and (by the nihilists' light) actually defeated by philosophical considerations. ${ }^{22}$ My second response is more straightforward: analytic deflationism is

\footnotetext{
${ }^{22}$ See Korman forthcoming and Eklund 2017 for a similar objection to analytic deflationism; see also deRosset 2015 for further relevant discussion.
} 
inconsistent with uncompromising Nihilism only because it is inconsistent with Nihilism per se. Since according to Nihilism there is matter arranged tiger-wise but no tigers, if the existence of the former is sufficient for the existence of the latter then Nihilism is false. This means that the uncompromising nihilist doesn't face any special challenge; anyone who believes that there is matter arranged tiger-wise but no tigers had better say something about what is wrong with analytic deflationism. But since my purpose in this paper is only to convince those who are already revisionary ontologists to adopt the uncompromising strategy, I will simply leave it to the nihilist to pick her favorite response.

Let's move on to the second worry. The causal component I offered looks a lot like an evolutionary debunking argument. Generally, debunking arguments attempt to show that beliefs about a certain subject matter have a bad epistemic status due to their etiology. ${ }^{23}$ But these arguments are notoriously controversial. Many philosophers resist some of their particular implementations, and some doubt that anything with the structure of an evolutionary debunking argument can be dialectically successful. ${ }^{24}$ However, I have not put forward the causal component as a debunking argument. Speaking in the abstract, debunking arguments make (1) an empirical claim about the origin of our beliefs about a subject matter and (2) an epistemological claim to the effect that our beliefs having that origin is evidence of some epistemic shortcoming (they are unjustified, unreliable, don't constitute knowledge, etc.).

${ }^{23}$ For debunking arguments in ethics, see Harman 1977: Ch. 1, Joyce 2006, Street 2006 and Clarke-Doane 2012; in mathematics, Benacerraf 1973, Field 1989: 25-30 and Clarke-Doane 2012; in logic, Schechter 2010; and in material-object metaphysics, Korman 2014, 2016: Ch. 7 and Benovsky 2015.

24 For domain-neutral objections to debunking arguments in general, see Williamson 2007: 220-241, White 2010, and Vavova 2014. 
But crucially, nowhere did I defend anything like (2) as it applies to perceptual ontological beliefs. I didn't say that the selective pressures that shaped our beliefs gave us any reason for abandoning them. I put the evolutionary story to a much more modest use: after the revisionist gave her favorite arguments for her position (not debunking arguments but arguments of the sort I will discuss in sections 3-5), she can address the Problem of Reasonableness by showing that there was no reason in the first place to expect evolution to select for truth-tracking ontological tendencies.

Now, while I didn't commit myself to the stronger claim that evolution selected for ordinary ontological tendencies, I also didn't rule out this possibility. And perhaps this stronger hypothesis would support a debunking argument of the sort I described above. This raises a version of the worry I introduced in the first section: if such a debunking argument is indeed available, it threatens to undermine the revisionist's arguments for her own view. I will address this worry in sections $4-5$, but before that, we need to provide the evaluative component.

\subsection{The evaluative component}

The evaluative component should explain why ordinary ontological beliefs are reasonable, despite being false. The details depend on various issues in epistemology that I cannot fully resolve in this paper. Still, I hope to say enough to show that one way or other, the uncompromising revisionist can provide a satisfactory evaluative component. I will exploit an analogy between ordinary people's situation according to revisionary ontologists and the New Evil Demon Problem (NEDP). ${ }^{25}$ The NEDP was originally raised as an objection to

\footnotetext{
25 The problem was first raised in Cohen and Lehrer 1983.
} 
reliabilism but can be seen more generally as an argument for mentalism about doxastic justification, the view that if two subjects are exact duplicates with respect to their nonfactive mental states, they cannot differ with respect to the justificatory status of their beliefs (in short: justification supervenes on non-factive mental states). ${ }^{26}$

The classic NEDP scenario asks us to imagine a world whose inhabitants have the same beliefs and experiences as ourselves but are systematically deceived by an evil demon. Barring potential complications stemming from externalism about mental content (which I will return to later), mentalists tend to believe that the Demon World's inhabitants share our epistemic outlook: their beliefs have the same justificatory status as ours. Most nonmentalists distinguish between justification and some other positive epistemic status and argue that although the beliefs of the Demon World's inhabitants aren't justified, they still have this other status. My strategy will be to argue that whatever we say about the Demon World's inhabitants, the revisionary ontologist can borrow that story and apply it to ordinary people in the actual world.

Let's start by distinguishing three possibilities in logical space:

(i) Ordinary World: Matter is arranged the way it appears to be, and common sense ontology is true and widely believed.

(ii) Revisionary World: Matter is arranged the way it appears to be, but common sense ontology is false (although widely believed).

\footnotetext{
${ }^{26}$ Cf. Wedgwood 2002. Conee and Feldman 2004 defend mentalism about propositional justification. In what follows, I will use the word 'justification' for doxastic justification and 'mentalism' for the doxastic thesis.
} 
(iii) Demon World: Matter isn't arranged the way it appears to be; this world's inhabitants are under the demon's spell.

Most ontologists believe that the conditions of composition are constant across possible worlds. I'm inclined to disagree ${ }^{27}$, but this shouldn't matter here, since by 'possibilities' I mean nothing more than coherently conceivable (even if perhaps metaphysically impossible) scenarios. By this, I don't mean that we can visually imagine worlds with different mereological principles (it's dubious that our visual imagination could distinguish between them) but only that it's coherent to conceive of a world where composition occurs under different conditions than in the actual world. Virtually all parties to the debate will grant at least this much, the only exception perhaps being analytic deflationists (see section 2.1). In fact, there is a way to make the argument that follows intelligible even for them: we can ask what the epistemic status of our beliefs would be in Revisionary World, given assumptions about what it would be in the Demon World. Since counterfactuals with impossible antecedents plausibly have non-trivial truth-values, we can evaluate such counterfactuals. ${ }^{28}$ This is all my

\footnotetext{
${ }^{27}$ My view is shared by Nolan (2005: 36), Cameron (2007), Miller (2009) and Parsons (2013).

28 This isn't uncontroversial. Williamson (2018), for instance, argues that allowing counterpossibles with nontrivial truth-values would come at too steep a price because (among other things) it would block counterfactual reductio ad absurdum proofs in mathematics. But there are ways of understanding metaphysical necessity that avoid Williamson's objection. For example, one might think of metaphysical necessity as a restricted notion of necessity and at the same time adopt a stronger (perhaps absolute) notion of necessity that does preserve the triviality of counterpossibles (see Clarke-Doane forthcoming). At any rate, it would be dogmatic to the extreme to insist that we have no way of making sense of the three scenarios depicted in (i)-(iii).
} 
argument for ordinary people's reasonableness will require. The argument itself is simple; it goes as follows:

\section{Argument for the Reasonableness of Ordinary Ontological Beliefs}

(O1) Ordinary people's ontological beliefs are reasonable, in some important sense of 'reasonable', in the Ordinary World

(O2) If ordinary people's ontological beliefs are reasonable in Ordinary World, they are also reasonable in the Demon World

(O3) If ordinary people's ontological beliefs are reasonable in Demon World, they are also reasonable in the Revisionary World

(O4) So, ordinary people are reasonable in the Revisionary World

I take O1 to be shared common ground between me and those who think that the Problem of Reasonableness is a serious challenge to revisionary ontology. If ordinary people's ontological beliefs are not reasonable, the Problem of Reasonableness doesn't get off the ground and revisionists have nothing to worry about. So, I will assume O1 without further argument.

O3 is perhaps less obvious, but still very plausible. The core intuition behind the NEDP is that while ordinary people's beliefs don't constitute knowledge, they are justified; save for the subject's epistemically hostile environment, they have as much going for them as they would in the Ordinary World. Of course, it's highly contentious whether this is enough for justification, and opponents of mentalism insist that it's exactly this hostile environment that makes a difference to the justificatory status of ordinary people's beliefs in the Demon World. However, this doesn't affect the conditional statement encapsulated in O3. With 
respect to ontological beliefs, the Revisionary World is very similar to the Demon World: it creates an epistemically hostile environment in which the objects that seem to exist aren't the objects that in fact exist. Since in other respects the Revisionary World is much less hostile than the Demon World, it's plausible that whatever positive epistemic status the beliefs of the Demon World's inhabitants have, the beliefs of the Revisionary world's inhabitants have that status as well. Thus, if ordinary people's beliefs are justified in the Demon World, they are also justified in the Revisionary World. Moreover, if mentalism is false and the beliefs of the Demon World's inhabitants are not justified but have some other kind of positive epistemic status, the beliefs of the Revisionary World's inhabitants plausibly have that status as well. Since it is this hypothetical positive status that I'm calling 'reasonableness', O3 is plausible too.

I expect the most controversial premise to be $\mathrm{O} 2$, which in effect says that there is a relevant epistemic status that obeys mentalist standards. So in what follows, I will argue for this premise. In doing so, I will try to stay as neutral as possible about substantive issues in epistemology; my goal is not to commit myself to any particular way of giving content to the elusive word 'reasonable' but only to show that the revisionary ontologist has plenty of options at her disposal. When presenting these options, I will mostly focus on ordinary people's beliefs about which objects do exist. This seems like the harder task, since a broadly inferential story will likely be available for negative existential beliefs. Nonetheless, I will indicate in the footnotes how abundant ontologists can employ the strategies presented below to interpret ordinary people's beliefs about which objects don't exist as reasonable, too.

Suppose mentalism is true. Then whatever justifies ordinary people's ontological beliefs will also justify the beliefs of the Demon World's inhabitants. Several candidates are available to the mentalist. Perhaps ordinary ontological beliefs are immediately justified by perceptual 
experiences as of ordinary objects. ${ }^{29}$ On this view, perceptual experience has rich content and already presents us with content about ordinary objects instantiating properties. ${ }^{30}$ Or perhaps perceptual experience is coarse-grained and presents us only with raw sensible qualities (e.g. shape and color) but still immediately justifies our ontological beliefs by noninferentially disposing us to form them. ${ }^{31}$ Alternatively, the justification of ordinary ontological beliefs may be mediate. Perhaps, for instance, they are justified through inference (or some unconscious, inference-like procedure) from perceptual experiences, rich or coarse. $^{32}$ The important feature these views share is that they all allow the mentalist to maintain that the mere falsity of a belief doesn't harm its justificatory status. Hence, the inhabitants of the Demon World, and a fortiori the Revisionary World, have justified ontological beliefs.

${ }^{29}$ See Pryor's (2000) and dogmatism and Huemer's (2001) phenomenal conservativism.

${ }^{30}$ By 'rich content', philosophers usually mean something stronger: content as of objects belonging to certain kinds (Siegel 2010: Chs. 4-5 and Masrour 2011). I don't want to enter a terminological dispute here. Suffice it to say that on some views we have perceptual experiences as of composite objects, while on others we don't.

31 See McGrath 2018 for this kind of view. For the coarse-grained view, see Bonjour 2003: 79. Silins (2013: 16 n4) argues that even if perceptual experience has no content (as according to Travis 2004), it could still immediately justify our beliefs.

32 See Fumerton 1995, Bonjour 2003, and Wright 2004. Some sort of inferential story looks like the most plausible account of ordinary beliefs about which objects don't exist. One such story would go roughly as follows. Ordinary people have perceptual experiences as of ordinary objects, but they never perceive any nonoccluded region of space as containing an extraordinary object. So (when the question arises), they infer that these regions don't contain extraordinary objects. Inferential beliefs of this sort are arguably justified by mentalist standards. 
This is a good place to revisit the wrinkle about content externalism I mentioned earlier. I described the Demon World as one whose inhabitants share our beliefs. But Majors and Sawyer (2005) have argued that externalism about mental content would rule this out, since the inhabitants lack causal contact with bits of reality they would need in order to acquire certain concepts necessary for forming these beliefs. Doesn't content externalism raise similar worries for uncompromising sparse revisionists? No, or at least none that is peculiar to the uncompromising approach. Content externalism leaves us with three options regarding the connection between ordinary object concepts and beliefs involving them. (1) Though the inhabitants of a sparse Revisionary World have no causal contact with ordinary objects, they have enough contact with the external world to share the object concepts of the Ordinary World's inhabitants (Merricks 2001: Ch. 1). If so, they can have (mostly false) beliefs about ordinary objects, as assumed throughout this paper. (2) A sparse Revisionary World's inhabitants lack some object concepts; for example, since they have no causal contact with $\mathrm{H}_{2} \mathrm{O}$ molecules, they don't have the concept water and a fortiori that of an $\mathrm{H}_{2} \mathrm{O}$ molecule (cf. Korman 2006) and express no proposition when uttering ' $\mathrm{H}_{2} \mathrm{O}$ '-sentences. In this case, we can reframe the original story in terms of ordinary people's justified/rational/blameless (etc.) tendency to utter sentences using ' $\mathrm{H}_{2} \mathrm{O}$ ' and other nonreferring terms. (3) Causal contact with qualified portions of matter doesn't merely equip us with ordinary object concepts but also makes our beliefs involving those concepts true. This is again our old friend analytic deflationism from section 2.1. As we have seen there, this view is indeed incompatible with the uncompromising strategy, but only because it's incompatible with sparse ontologies as such. All sparse ontologists have to find a way to resist analytic deflationism. 
Back to our main thread: what should the revisionist say if mentalism is false? Although most non-mentalists believe that the Demon World's inhabitants have unjustified beliefs, they can still agree that the inhabitants are doing well along some dimension of epistemic evaluation. The revisionary ontologist can coopt these strategies and argue that ordinary people are doing well in exactly the same sense in the Ordinary World.

One familiar non-mentalist strategy is to distinguish justification from an evaluative concept in the vicinity that does obey mentalistic standards. Many such candidates have been discussed in the literature: rationality ${ }^{33}$, reasonableness (in a more technical sense than what I have been operating with) ${ }^{34}$, personal justification ${ }^{35}$, etc. (some of these might come to the same thing, but this is irrelevant for my present purposes). These notions were all introduced to capture an evaluative property whose possession is completely up to the subject.

A second non-mentalist approach distinguishes justification from a weaker notion, which accurately characterizes the Demon World's inhabitants but (unlike the mentalistic concepts mentioned above) still makes reference to the environment. Sosa's (2003) notion of adroit justification fits this template: according to him, the beliefs of the Demon World's inhabitants are adroit-justified, meaning that they were acquired through the exercise of an intellectual virtue which nonetheless led the inhabitants astray due to the epistemically inhospitable environment. If the environment contained ordinary objects, the inhabitants' beliefs would be fully justified or, in Sosa’s terminology, "apt-justified".

A third non-mentalist strategy distinguishes justification from a purely ameliorative epistemic property: beliefs with the property don't necessarily have anything going for them,

33 Goldman 1986

${ }^{34}$ Littlejohn 2009

35 Bach 1985, Engel 1992 
but have less going against them than beliefs without it. Natural candidates for playing this role include subjective epistemic blamelessness ${ }^{36}$ and epistemic excusability ${ }^{37}$. Perhaps the beliefs of the Demon World's inhabitants are unjustified, even irrational; yet they are excusable/blameless: the inhabitants violated their epistemic obligations, but the violation should be excused because it wasn't up to them to avoid it.

The above discussion wasn't intended to exhaust the range of options for how to interpret 'reasonable', but I hopefully said enough to make O2 plausible. This closes my defense of the Argument for the Reasonableness of Ordinary Beliefs. The argument suggests the following general strategy for meeting the evaluative component's explanatory demands. First, pick your favorite theory of epistemic justification and see what it says about the NEDP; if necessary, also figure out what other kind of positive or ameliorative epistemic status you would like to ascribe to the beliefs of the Demon World's inhabitants. Then apply these results to ordinary people in the Revisionary World. Finally, argue that the Revisionary World is our world.

This way of proceeding also helps address some natural objections. For example, one might worry that it's too easy for a belief to be excusable. Beliefs formed as a result of brainwashing also seem excusable; surely, though, ordinary ontological beliefs have more going for them than beliefs caused by brainwashing! However, to the extent that objections of this kind have force, they should be seen as posing a problem not to the uncompromising strategy but to the accompanying epistemological view. Given O2, the plausibility of an epistemological view's treatment of ordinary ontological beliefs stands or falls with the

${ }^{36}$ Goldman 1988

37 Williamson 2000: 257 
plausibility of that same view's treatment of the NEDP; if the metaphysically uninitiated are doing better than the brainwashed, so are the Demon World's inhabitants. ${ }^{38}$ But while being an uncompromising revisionist is optional, everyone has to say something about the NEDP. So even if an epistemological view has implausible consequences for the status of ordinary people's ontological beliefs, this is no extra cost over and above the same view's consequences for the NEDP. If the cost is worth paying there, it's also worth paying in the case of revisionary ontology; if it isn't, then we should abandon it anyway and combine the uncompromising strategy with a more plausible epistemology.

We are now ready to state the uncompromising solution to the Problem of Reasonableness. Ordinary ontological beliefs are explained by selective mechanisms that were independent of the ontological truth. Though in itself this doesn't imply that these beliefs are false, the revisionist's arguments (some of which we will review in sections 3-5) show that they are in fact false. Yet these beliefs are reasonable in the sense that on a wide range of views, they satisfy a mentalist criterion of favorable epistemic evaluation. This is how ordinary people ended up with large swathes of false, albeit reasonable, ontological beliefs.

\section{The Backfiring Challenge}

One might object to my two-pronged solution along the following lines. If ordinary people's ontological beliefs were shaped in the way I described above, they cannot rationally maintain those beliefs once they learn of their origin. This might seem to give the revisionist an edge,

\footnotetext{
${ }^{38}$ See Cohen and Comesaña forthcoming for the analogous worry about ameliorative treatments of the NEDP and Littlejohn forthcoming for a response.
} 
since her ontological beliefs are based on theoretical considerations. But, the objector could continue, the revisionary ontologist's beliefs aren't any less affected than ordinary people's, since they are based on arguments that cannot avoid ultimately relying on perceptual ontological beliefs (perhaps nihilists are off the hook). To be clear, the worry isn't that $I$ am somehow committed to a debunking argument that undermines the revisionist's arguments (see section 2.1). The worry instead is that whatever my own view is, some such argument is sound and undermines the revisionist's project. Call this the Backfiring Challenge.

Korman (2014, 2016: Ch. 7) endorses something like the Backfiring Challenge. My formulation of his argument largely follows his $\mathrm{own}^{39}$ :

\section{Perceptual Debunking Argument}

(D1) There is no (nondeviant) explanatory connection between ordinary people's perceptual ontological beliefs and the ontological truth ${ }^{40}$

(D2) If so, then once they learn of this, ordinary people cannot rationally maintain their perceptual ontological beliefs

(D3) So, once ordinary people learn that there is no nondeviant explanatory connection between their perceptual ontological beliefs and the ontological truth, they cannot rationally maintain these beliefs

\footnotetext{
${ }^{39}$ Korman doesn't believe that the argument is sound but argues that rebutting it requires radical measures: we would need to embrace anti-realism, theism, or a special faculty of apprehension (he goes for the last option).

${ }^{40}$ Korman uses the expressions 'object belief' and 'object fact'. Unlike my 'ontological belief' and 'ontological truth', these only refer to beliefs and facts about which objects do exist.we
} 
Korman's argument for D1 is similar to my causal component: our perceptual ontological beliefs are explained by evolutionary and cultural factors that are independent of the ontological truth. As I earlier mentioned, it's controversial whether we can get from a debunking argument's empirical claim to its epistemological claim, and in the present case from D1 to D2's consequent. Korman thinks we can, and for the argument's sake I will grant this in what follows. Then, he argues, the revisionist is in trouble. We can begin to see why by considering the following popular argument for Universalism:

\section{Argument from Vagueness}

(V1) Vague composition is impossible

(V2) If V1, then either every plurality of objects composes something or none do

(V3) Some pluralities of objects compose something

(V4) So, every plurality of objects composes something. So, Universalism is true. ${ }^{41}$

The controversial premises in this argument are V1 and V2. Indeed, proponents of the argument don't just take these premises for granted but argue for them in detail (see especially Sider 2001: 120-139). What they typically don't argue for is V3: standard presentations of the argument simply assume that some pluralities of objects compose something. But, Korman argues, if the Perceptual Debunking Argument is sound, this premise cannot be taken for granted. For even though the support for the other premises is

\footnotetext{
${ }^{41}$ The argument was first proposed by Lewis (1986: 211-212) and then refined and generalized by Sider (2001: 120-139).
} 
theoretical, universalists can accept V3 only on the basis of perception, which the Perceptual Debunking Argument teaches us not to trust on such matters.

Similar considerations apply to other arguments for Universalism, for example the

\section{Argument from Arbitrariness}

(A1) There is no ontologically significant difference between scattered artifacts and fusions of any arbitrary $x s$; if the former exist, so do the latter

(A2) There are scattered artifacts

(A3) So, any $x$ s have a fusion. So, Universalism is true. ${ }^{42}$

Here, too, while the controversial premise is A1, the real culprit is A2 since the universalist can only accept it on perceptual grounds. But if the Perceptual Debunking Argument is sound, we cannot accept A2 on that basis.

Korman mainly focuses on abundant ontologies, but in so far as they rely on debunked premises, similar problems arise for most sparse views. If we take the Perceptual Debunking Argument seriously, we cannot assume at the outset that ordinary objects of this or that sort exist and then argue for some modification of common sense ontology. In the next section I will argue that even if the Perceptual Debunking Argument is sound (something that, recall, I'm agnostic about), it doesn't threaten the standard arguments for revisionary views. This is because, pace Korman, the best versions of these arguments don't rely on perceptual ontological beliefs.

42 Cf. Rea 1998 and Hawley 2001: 6-7. This is only one possible formulation of the argument; I will defend a different one in section 5. Korman presents the argument as a general line for plenitudinous ontologies, but here I'm concerned only with Universalism. 


\section{Organicism undebunked}

According to van Inwagen, the only composite objects are biological organisms:

Organicism: There is a $y$ that the $x$ s compose if and only if the activity of the $x \mathrm{~s}$ constitutes a life (van Inwagen 1990: 82)

In Chapter 12 of Material Beings, he offers the following argument for Organicism. First, we know that some composite objects exist because we know that we exist, and we aren't immaterial. So the particles arranged human-wise in the region where I sit compose a material object (1990: 115-120). Why? The best explanation is that their activity constitutes a life. However, life-constitution isn't peculiar to particles arranged human-wise; so lower-level organisms exist, too (120-122). Thus, life-constitution is sufficient for composition. Is it also necessary? Van Inwagen offers three reasons for thinking so. First, explaining our own existence in terms of life-constitution doesn't force us to posit inanimate objects, and parsimony considerations tell against their existence. Second, no rival view would generate exactly those objects whose existence we would intuitively accept, so none of Organicism's alternatives should be preferred on intuitive grounds. Third, inanimate objects generate puzzles that don't arise for living beings.

As it stands, the argument isn't debunking-safe, since it appeals to intuitions plausibly affected by the same factors that affected our perceptual ontological beliefs. As I will show, however, we can fix the argument to circumvent this worry. Let's begin with the argument's first half, which tries to establish that we are composite material objects: 


\section{The Cogito Argument}

(P1) I exist

(P2) If I exist, I'm either material or immaterial

(P3) I'm not immaterial

(P4) If I'm material, I'm either a composite object or a simple

(P5) I'm not a simple

(C1) So, I'm a composite material object

We don't need to fully evaluate the Cogito Argument here; it's enough to show that it doesn't have debunked premises. P1 relies either on introspective evidence of my own existence, or introspective evidence of my own thinking and the principle that no thought could exist without a thinker. Either way, while not uncontroversial, this premise doesn't rely on perceptual experience as of ordinary objects. ${ }^{43} \mathrm{P} 2$ and $\mathrm{P} 4$ are trivial. P3 can be supported by whatever you think the best arguments are against substance dualism, idealism, and the view that ' $\mathrm{I}$ ' is a syntactically singular but semantically plural term. I don't mean to dogmatically assert that these arguments are conclusive; I just want to emphasize that they don't rely on perceptual ontological beliefs. P5 can be supported by the same intuitions that motivate P1. Plausibly, for any particular simple, my conscious states could exist without that simple existing. However, there can be no thought without a thinker; so, the thinker that has my conscious states cannot be identical to any of these simples. Again, while this motivation for P5 is contestable, it isn't based on perceptual ontological beliefs.

\footnotetext{
${ }^{43}$ Korman (2014: 10 n29; 2016: 104 n22) expresses some doubts about this but concedes that a similar argument by Merricks might survive debunking (2016: 96-97 n11).
} 
The next few steps get us from C1 to Organicism:

(P6) If I'm a composite material object, then the particles that compose me do so either (a) because their activity gives rise to thinking or (b) because their activity constitutes a life or (c) for some other reason (e.g. Contact, Fastening, Cohesion, Fusion, Universalism)

(P7) (a) is false

(P8) The (c)-answers give rise to puzzles that (b) avoids

These premises, too, are debunking-safe. P7 relies on C1 and intuitions about what could explain my parts' composing something. Though controversial, these are counterfactual intuitions about what would explain the existence of composite material objects if any existed. The thought behind P6 is that there is a principled account of when and why composition occurs. One may well take issue with this assumption (see Markosian 1998), but it's clearly based on general methodological considerations rather than perceptual ontological beliefs. P8 seems safe, too. Though many puzzles of material constitution arise for organisms ${ }^{44}$, some arise only for artifacts (for instance, there is no "Ship of Theseus"-style puzzle about living organisms).

Now we have reached the critical point where the original argument must be modified. Van Inwagen rules out (c)-views in part because they are no less at odds with our intuitions than Organicism is. If sound, the Perceptual Debunking Argument undermines this motivation. However, we can still compare Organicism to its rivals on the basis of how well

${ }^{44}$ See Eklund 2002: 249-252 
they cohere with ontological beliefs we have reason to keep on the basis of P1-P7. Call such beliefs saved. Then the argument can be continued as follows:

P9) (c)-views aren't compatible with more of our saved ontological beliefs than (b) is

P10) If (c)-views aren't compatible with more of our saved ontological beliefs than (b) is but give rise to puzzles that (b) avoids, then (c)-views are false

From P1-P10 we can derive Organicism. This concludes my reconstruction of van Inwagen's argument, which, we have seen, can be based entirely on debunking-safe premises. In fact, the Perceptual Debunking Argument improves the organicist's dialectical position. Van Inwagen's claim that Organicism is at least as intuitive as its rivals is contestable (Hudson 2001: 108); it's much harder to take issue with the claim that Organicism does a good job respecting those ontological beliefs that we have reason to hold on the basis of P1-P7.

It goes without saying that van Inwagen's argument has several controversial premises. However, this is irrelevant to my present point. I'm not endorsing the argument; I merely point out that nobody who finds Organicism plausible on the basis of my reconstructed version should stop finding it plausible because of the Perceptual Debunking Argument. As it turns out, the organicist's situation is nothing special: in the next section, I will argue that the core arguments for Universalism also survive debunking.

\section{Universalism undebunked}

In this section, I will argue that the Perceptual Debunking Argument also allows universalists to keep their favorite arguments. First, however, I need to reformulate one of these 
arguments. Recall that according to A2 of the Argument from Arbitrariness, there are scattered artifacts. I don't know how to defend this premise other than on perceptual grounds, but there is a version of the argument that doesn't have this problem. It goes as follows:

\section{Revised Argument from Arbitrariness}

(R1) If some non-degenerate (more than one-membered) pluralities compose an object, that object is scattered (most of what falls within the boundaries of an object is empty space)

(R2) Some non-degenerate pluralities compose an object

(R3) If composite objects are scattered, then whether they are visibly scattered doesn't make an ontologically significant difference

(R4) If all objects are scattered and the visibility of their scatteredness doesn't make an ontologically significant difference, then if some pluralities compose an object, all pluralities do

(R5) So, all non-degenerate pluralities compose an object. So, Universalism is true. $^{45}$

This revised argument raises two questions. First, is R2 defensible on non-perceptual grounds? Second, is R3 as compelling as A2, given that it no longer appeals to some particular kind of object we are already inclined to believe in? I will address the first question

\footnotetext{
${ }^{45}$ Although this version of the Argument from Arbitrariness is less well known than the one I considered in section 3 it has been endorsed by Hudson (2001: 108) and Moyer (2006: 408), among others.
} 
momentarily; before doing so, I want to say a few words about the second. One way to think of arbitrariness arguments is as merely requesting general principles. This is the thought behind A2: it asks us to draw the line between scattered artifacts and arbitrary fusions in a principled way, but it doesn't impose external constraints on which principled ways of drawing the line are acceptable. The Revised Argument works differently. R1 borrows its plausibility from the fact that material objects look quite different in the "manifest image" than in the "scientific image". And then R3 demands that we draw the lines in synch with the scientific image.

To my mind, this reasoning looks more persuasive from a universalist perspective. Arbitrariness arguments are often presented as attacking the anthropocentrism of common sense ontology, but R3 gives better justice to this rhetoric than A2. A2 asks us to not exclude certain things from our ontology, but only because we already believe in some other things. By contrast, R3 asks us to not exclude visibly scattered objects because basing our judgments on which objects seem scattered to us is entirely arbitrary and anthropocentric. While the first arbitrariness argument focuses on the unsystematic nature of our ontological beliefs, the second one focuses on their provinciality. The first argument may be more popular, but the second strikes me as more powerful.

Next, I will argue that the universalist can give at least two debunking-safe arguments for R2 (=V3), the premise of the Argument from Vagueness and the Revised Argument from Arbitrariness that asserts the existence of some composite objects. The first, the Cogito Argument, we already know. The second is based on the possibility of gunk (Sider 1993) and goes as follows: 


\section{The Argument from the Possibility of Gunk}

(G1) Possibly, there is gunk

(G2) If possibly, there is gunk, Nihilism is possibly false

(G3) If Nihilism is possibly false, then Nihilism is false

(G4) So, Nihilism is false; so, some objects have a fusion

Korman objects that the thought behind G3 is that if composition occurs in any possible world, surely the actual world is one of them. "But where could this conviction be coming from," he asks, "if not from experiences that represent stuff arranged treewise as making up a single object?” (2014: 10).

Now, G3 is standardly motivated by appeal not to perceptual experience but the intuition that as a "proposition of metaphysics" Nihilism is necessarily true, if true at all (Sider 1993; 2013: \$10). Korman recognizes this but contends that we still need a reason for thinking that Nihilism is false even once we accept that it's possibly false. After all, Nihilism is true in a possible world that contains only one simple, but this wouldn't make Nihilism true in the actual world. Similarly, the mere possible falsity of Nihilism, i.e. G3's antecedent, by itself gives us no reason to accept its actual falsity, i.e. G3's consequent (2016: 104). Hence the need to ultimately base G3's consequent on perception.

Suppose for the argument's sake that Korman is right: our justification for G3 depends on our justification for its consequent. This would indeed undermine the argument, but for reasons that have nothing to do with perceptual debunking. Rather, since G3's consequent is simply the argument's conclusion, if our justification for G3 depended on it, the argument would be circular. I doubt that this is the case but won't argue the point here; either way, advocates of the Argument from the Possibility of Gunk have no special problem with 
perceptual debunking. Either our justification of G3 ultimately depends on G4 or not. If it doesn't, the argument hasn't been shown to rest on debunked premises; if it does, the argument is circular no matter how else we might want to justify G4.

None of this is to say that the argument is impeccable. ${ }^{46}$ However, my goal has not been to defend the argument. All I claim is that it has no debunked premise; at no point does it assume anything the Perceptual Debunking Argument threatens to undermine.

At best, the Perceptual Debunking Argument shows that universalists cannot simply assume that there are ordinary objects and argue from there to the conclusion that there are also extraordinary ones. But we already knew this: Nihilism is a serious if unpopular view, so revisionists cannot assume its falsity without argument. Luckily, they don't have to: they can make their arguments debunking-resistant by relying on the Cogito Argument or the Argument from the Possibility of Gunk. So even if sound, the Perceptual Debunking Argument doesn't prevent most universalists from relying on their favorite arguments.

\section{Now what?}

I defended an uncompromising solution to the Problem of Reasonableness: the selective mechanisms that shaped our tendencies to form ontological beliefs were independent of the ontological truth, yet these beliefs are reasonable at least in whatever sense the beliefs of the Demon World's inhabitants are. I also argued that revisionists could endorse this view without taking a stance on the Perceptual Debunking Argument, since even if sound, that argument doesn't undermine the revisionist's arguments.

\footnotetext{
46 See Williams 2006 and Sider 2013 against G1, and Cameron 2007 and Miller 2009 against G3.
} 
While the arguments discussed in sections 3-5 don't rely on perceptual ontological beliefs, they often rely on introspection, modal intuition, and various a priori principles. This raises the question of whether other debunking arguments threaten our non-perceptual ontological beliefs. I cannot answer this important question here; I just point out that it brings nothing new to the table. The concerns with these sources of evidence are familiar, and the uncompromising revisionist may well have to answer tough questions about them. But then again all revisionists need to address these concerns, whatever their preferred solution is to the Problem of Reasonableness.

A potential residual concern is that if the Perceptual Debunking Argument is sound, similar considerations might undermine our other sources of justification to believe in composite material objects. This worry could be fully addressed only by developing a complete (non-perceptual) epistemology of material-object metaphysics. That is a task too large to undertake here, so I will resort to a couple of brief remarks. First: in the arguments I attempted to un-debunk above, there is no need to base all ontological beliefs on the same source of justification, and some of the sources in question might not even be basic. Take, for instance, the general principle I offered in defense of P5 (and of P1, at least to some extent): that there is no thought without a thinker. Plausibly, a principle of this sort is justified not by any basic source of justification but by inference to the best explanation. A possible just-so story could go like this: pluralities of thinkers (such as you and me taken together) cannot collectively have thoughts; the best explanation of this fact is that they are pluralities rather than individual things; and therefore, pluralities of smaller things cannot 
collectively have thoughts either. So, every thought requires a thinker, an individual object. ${ }^{47}$ The second remark I wish to make is that the undebunked sources of justification need not be easily available for non-philosophers. For example, ordinary people rarely acquire their ontological beliefs via inference to the best explanation; isn't this a problem? Not in the present context. Indeed, those sympathetic to my approach should expect exactly this result. Part of what it takes to be an uncompromising ontologist is to come to grips with the fact that which material objects there are is a difficult philosophical question; it is no surprise, then, that philosophers are better equipped to answer it than most.

The uncompromising revisionist faces one more pressing question: how should we talk about ordinary objects? Here, abundant ontologists have an easier task: they can assert sentences like 'Rock-dogs don't exist'; they should just add that in so doing they speak loosely. As I indicated in section 1, the various "loose talk" strategies are problematic qua empirical hypotheses about ordinary discourse. But this shouldn't prevent the revisionist from speaking loosely.

Sparse ontologists need some other strategy. To them, I recommend going fictionalist: they should mentally prefix their utterances with "according to the fiction of common sense ontology". "So the revisionist only has to change her beliefs, not her behavior: she can switch from outright belief in ordinary objects to the belief that, according to the fiction of common sense ontology, there are such and such objects. This is entirely compatible with

\footnotetext{
${ }^{47}$ The argument is reminiscent of one given by Barnett (2010), though importantly, he sets out to explain why pairs of people cannot be conscious, proposes that it's because they aren't simple, and concludes that we are simple too. I find this argument much less convincing than the analogous argument for the claim that thoughts require a thinker.

${ }^{48}$ Cf. Merricks 2001: Ch. 7, Rosen and Dorr 2002
} 
the recognition that becoming an uncompromising revisionary ontologist involves a thoroughgoing revision of one's beliefs and perhaps, strictly speaking, even one's breakfast plans. 


\section{References}

Alvarez, George A. (2011), "Representing multiple objects as an ensemble enhances visual cognition," Trends in Cognitive Sciences, 15: 122-31

Barnett, David (2010), "You are simple," Robert C. Koons \& George Bealer (eds.), The Waning of Materialism, Oxford University Press, 161-174

Benacerraf, Paul (1973), "Mathematical Truth,” Journal of Philosophy, 70: 661-79

Bennett, Karen (2009), "Composition, Colocation, and Metaontology," in David Chalmers, David Manley and Ryan Wasserman (eds.) (2009), Metametaphysics, Oxford: Oxford University Press, pp. 38-76

Benovsky, Jiri (2015), “From Experience to Metaphysics,” Noûs, 49: 684-97

Bonjour, Laurence (2003), “A Version of Internalist Foundationalism,” in Laurence Bonjour and Ernest Sosa, Epistemic Justification, Oxford: Blackwell

Cameron, Ross P. (2007), "The contingency of composition,” Philosophical Studies, 136: 99 121

Cameron, Ross P. (2008), "Truthmakers and ontological commitment," Philosophical Studies, 140: $1-18$

Cameron, Ross P. (2010), "Quantification, Naturalness and Ontology," in Allan Hazlett (ed.), New Waves in Metaphysics, New York: Palgrave-Macmillan, pp. 8-26.

Chisholm, Roderick M. (1976), Person and Object, London: George Allen and Unwin Clarke-Doane, Justin (2012), "Morality and Mathematics: The Evolutionary Challenge," Ethics, 122: 313-340

Clarke-Doane, Justin (forthcoming), “Modal Objectivity,” Noûs 
Cohen, Stewart and Juan Comesaña (forthcoming), "Being Rational and Being Right," in Julien Dutant and Fabian Dorsch (eds), The New Evil Demon Problem, Oxford University Press

Cohen, Stewart and Keith Lehrer (1983), “Justification, Truth, and Coherence," Synthese, 55: $191-207$

Conee, Earl and Richard Feldman (2004), Evidentialism, New York: Oxford University Press deRosset, Louis (2015), “Analyticity and ontology," Oxford Studies in Metaphysics, 9: 129_ 70

Dorr, Cian (2005), "What We Disagree About When We Disagree About Ontology," in Mark Eli Kalderon (ed.), Fictionalism in Metaphysics, Oxford: Clarendon Press, pp. 234 286

Eklund, Matti (2002), "Peter van Inwagen on Material Beings,” Ratio, 15: 245-256

Eklund, Matti (2005), "Fiction, Indifference, and Ontology," Philosophy and Phenomenological Research, 71: 557-579

Eklund, Matti (2017), “Review of 'Ontology Made Easy' by Amie L. Thomasson,” Notre Dame Philosophical Review <URL: https://ndpr.nd.edu/news/ontology-made-easy/>

Engel, Mylan (1992), "Personal and Doxastic Justification," Philosophical Studies, 67: 133-150

Field, Hartry (1989), Realism, Mathematics, and Modality, Oxford: Blackwell

Fumerton, Richard A. (1995), Metaepistemology and Skepticism, Rowman and Littlefield

Goldman, Alvin (1986), Epistemology and Cognition, Cambridge, MA: Harvard University Press Goldman, Alvin (1988), "Strong and Weak Justification," Philosophical Perspectives, 2: 51-69

Harman, Gilbert (1977), The Nature of Morality, New York: Oxford University Press

Hawley, Katherine (2001), How Things Persist, Oxford: Oxford University Press

Heller, Mark (1990), The Ontology of Physical Objects, New York: Cambridge University Press 
Hirsch, Eli (2002), “Against Revisionary Ontology,” Philosophical Topics, 30: 103-127

Hirsch, Eli (2005), "Physical-Object Ontology, Verbal Disputes, and Common Sense," Philosophy and Penomenological Research, 70: 67-97

Horgan, Terence and Matjaž Potrč (2008), Austere Realism, Cambridge: MIT Press

Hudson, Hud (2001), A Materialist Metaphysics of the Human Person, Ithaca: Cornell University Press

Huemer, Michael (2001), Skepticism and the Veil of Perception, Lanham: Rowman \& Littlefield Joyce, Richard (2006), The Evolution of Morality, Cambridge: MIT

Keller, John A. (2015), "Semantics, Paraphrase, and Ontology," Oxford Studies in Metaphysics, 9: 89-128

Korman, Daniel Z. (2006), "What Externalists Should Say About Dry Earth," Journal of Philosophy, 103: 503-20

Korman, Daniel Z. (2008), "Unrestricted Composition and Restricted Quantification," Philosophical Studies, 140: 319-334

Korman, Daniel Z. (2009), "Eliminativism and the Challenge from Folk Belief," Noûs, 43: 242-264

Korman, Daniel Z. (2014), "Debunking Perceptual Beliefs about Ordinary Objects," Philosophers' Imprint, 14 (13)

Korman, Daniel Z. (2015), "Fundamental Quantification and the Language of the Ontology Room," Nô̂s, 49: 298-321

Korman, Daniel Z. (2016), Objects: Nothing Out of the Ordinary, Oxford: Oxford University Press 
Korman, Daniel Z. (forthcoming), "Easy Ontology without Deflationary Metaontology," Philosophy and Phenomenological Research

Korman, Daniel Z. \& Chad Carmichael (2017), "What Do the Folk Think about Composition and Does It Matter?," in David Rose (ed.), Experimental Metaphysics, Bloomsbury, pp. 187-206

Lewis, David K. (1986), On the Plurality of Worlds, Malden: Blackwell

Liggins, David (2008), "Nihilism without self-contradiction," Royal Institute of Philosophy Supplement, 62: 177-196

Littlejohn, Clayton (2009), “The Externalist's Demon,” Canadian Journal of Philosopby, 39: $399-434$

Littlejohn, Clayton (forthcoming), "A Plea for Epistemic Excuses," in Dutant and Dorsch Majors, Brad and Sarah Sawyer (2005), "The Epistemological Argument for Content Externalism," Philosophical Perspectives, 19: 257-80

Markosian, Ned (1998), "Brutal Composition,” Philosophical Studies, 92: 211-249

Masrour, Farid (2011), “Is Perceptual Phenomenology Thin?," Philosophy and Phenomenological Research, 83: 366-397

McGrath, Matthew (2005), "No Objects, No Problem?,” Australasian Journal of Philosophy, 83: $457-486$

McGrath, Matthew (2008), "Conciliatory metaontology and the vindication of common sense," Noûs, 42: 482-508

McGrath, Matthew (2018), "Looks and Perceptual Justification," Philosophy and Phenomenological Research, 96: 110-133

Merricks, Trenton (2001), Objects and Persons, New York: Oxford Miller, Kristie (2009), "Defending Contingentism in Metaphysics,” Dialectica, 63: 23-49 
Moyer, Mark (2006), “Statues and Lumps: A Strange Coincidence,” Synthese, 148: 401-423

Nolan, Daniel (2005), David Lewis, Chesham: Acumen

O'Leary-Hawthorne, John and Michaelis Michael (1996), "Compatibilist semantics in metaphysics: A case study," Australasian Journal of Philosophy, 74: 117-134

Osborne, Robert Carry (2016), "Debunking Rationalist Defenses of Common-Sense Ontology: An Empirical Approach,” Review of Philosophy and Psychology, 7: 197-221

Parsons, Josh (2013), “Conceptual conservativism and contingent composition,” Inquiry, 56: $327-339$

Pryor, James (2000), “The skeptic and the dogmatist,” Nô̂s, 34: 517-49

Rea, Michael C. (1998), "In Defense of Mereological Universalism," Philosophy and Phenomenological Research, 58: 347-360

Rose, David and Jonathan Schaffer (2017), "Folk Mereology is Teleological," Noûs, 51: 23870

Rosen, Gideon and Cian Dorr (2002), "Composition as a Fiction,” in Richard M. Gale (ed.), The Blackwell Guide to Metaphysics, Oxford: Blackwell, pp. 151-174

Roskies, Adina L. (1999), “The Binding Problem,” Neuron, 24: 7-9

Sattig, Thomas (2015), The Double Lives of Objects: An Essay in the Metaphysics of the Ordinary World, Oxford: Oxford University Press

Schaffer, Jonathan (2009), "On what grounds what," in Chalmers et al, pp. 347-83

Schechter, Joshua (2010), "The Reliability Challenge and the Epistemology of Logic," Philosophical Perspectives, 24: 437-464

Sider, Theodore (1993), "Van Inwagen and the Possibility of Gunk," Analysis, 53: 285-289

Sider, Theodore (2001), Four-Dimensionalism, Oxford: Clarendon Press

Sider, Theodore (2011), Writing the Book of the World, Oxford: Oxford University Press 
Sider, Theodore (2013), "Against Parthood," Oxford Studies in Metaphysics, 8: 237-93

Siegel, Susanna (2010), The Contents of Perceptual Experience, Oxford: Oxford University Press

Silins, Nicholas (2013), “The Significance of High-Level Content,” Philosophical Studies, 162: $13-33$

Singh, Manish and Donald D. Hoffman (2013), "Natural Selection and Shape Perception," in Sven J. Dickinson and Zygmunt Pizlo (eds.), Shape Perception in Human and Computer Vision, Dordrecht: Springer, pp. 171-85

Sosa, Ernest (2003), Epistemic Justification: Internalism vs. Externalism, Foundations vs. Virtues, Malden, MA: Blackwell

Spelke, Elizabeth S. (1990), "Principles of Object Perception," Cognitive Science, 14: 29-56

Street, Sharon (2006), “A Darwinian Dilemma for Realist Theories of Value," Philosophical Studies, 127: 109-166

Taraborelli Dario (2002), "Feature Binding and Object Perception. Does Object Awareness Require Feature Conjunction?," European Society for Philosophy and Psychology 2002, Jul 2002, Lyon, France. <ijn 00000311>

Thomasson, Amie L. (2007), Ordinary Objects, Oxford: Oxford University Press

Thomasson, Amie L. (2015), Ontology made Easy, Oxford: Oxford University Press

Travis, Charles (2004), “The Silence of the Senses,” Mind, 113: 57-94

Unger, Peter (1979), “There Are No Ordinary Things,” Synthese, 41: 117-154

Uzquiano, Gabriel (2004), "Plurals and Simples," Monist, 87: 429-451

van Cleve, James (1986), "Mereological Essentialism, Mereological Conjunctivism, and Identity Through Time," Midwest Studies in Philosophy, 11: 141-156

van Inwagen, Peter (1990), Material Beings, Ithaca: Cornell 
van Inwagen, Peter (2014), "Introduction: inside and outside the ontology room," in Existence, Cambridge: Cambridge University Press, pp. 1-14

Vavova, Ekaterina (2014), "Debunking evolutionary debunking," Oxford Studies in Metaethics, 9: 76-101

Wedgwood, Ralph (2002), "Internalism Explained," Philosophy and Phenomenological Research, 65: 349-69

White, Roger (2010), "You just believe that because...," Philosophical Perspectives, 24: 573-615

Williams, J.R.G. (2006), “Illusions of Gunk,” Philosophical Perspectives, 20: 493-513

Williamson, Timothy (2000), Knowledge and its Limits, Oxford: Oxford University Press

Williamson, Timothy (2007), The Philosophy of Philosophy, Oxford: Oxford University Press

Williamson, Timothy (2018), “Counterpossibles,” Topoi, 37: 357-68 